\title{
Transfusion Transmissible Diseases Among Healthy Blood Donors Attended at Transfusion Medicine Department of DMCH in 2014
}

\author{
*S Karim ${ }^{1}$, E Hoque $^{2}$, MM Hoque $^{3}$ \\ $1 *$ Dr. Shanaz Karim, Assistent Professor, Department of Transfusion Medicine, DMCH \\ ${ }^{2}$ Dr. Ehteshamul Hoque, Professor, Department of Oncology, AKMMCH \\ ${ }^{3}$ Dr. Mazharul Hoque, Professor, Department of Transfusion Medicine, DMCH
}

*Corresponding Author

Date of submission: 02 February 2015

Date of acceptance:14 November 2015

\begin{abstract}
Background: This study was carried out to find out the seropositive of HBV, HCV, HIV, Treponema pallidum and Malarial parasite among the blood donors attended at transfusion medicine department of DMCH in 2014. Our objective is to prevent the spread of Transfusion transmissible disease through blood transfusion and awareness of mass population about TTI.
\end{abstract}

Method: This study was carried out at transfusion medicine department of DMCH from 1st January 2014 to 31 st December 2014.Total blood donors were 39,512. Blood donors of 18 - 60 years of both sexes were included in this study.

Results: Among 39,512 blood donors relative blood donors were 32,778(82.95\%), voluntary blood donors were 6734.( 17.04\% Among 39,512 blood donors , HBsAg positive 456 (1.154\%), Anti HCV positive 33(.090\%), Malarial Parasite positive 04 (.010), Treponema pallidum positive $87(.220 \%)$ and positive for HIV 01(.0025\%)

Conclusion: Prevention of spread of TTIs should be the main goal at the current time. It is important to follow the WHO guidelines to tests every donor for HBV, HCV, HIV and Syphilis to decrease the transmission of TTIs.

Key Words: Blood donor, Voluntary donor, Relative donor, Screening. TTI

\section{Introduction}

Donated blood can be life saving for individual who have severely anemic due to any cause. Blood transfusion can cause transmission of infected blood donated by apparently healthy and asymptomatic blood donors. Screening of blood donors helps to ensure that the donated blood is save for transfusion into a recipients.

The first case of transfusion-associated AIDS was described in an infant given transfusion for erythroblastosis foetalis. ${ }^{1}$ Globally, more than 81 million units of blood are donated each year ${ }^{2}$ More than 18 million units of blood are not screened for transfusion-transmissible infections ${ }^{1}$. According to World Health Organization (WHO), in the year of 2006 only 38 countries were collecting more than $75 \%$ of their blood supplies from families, the rest obtained it from professional blood donors on payment.

WHO recommends that, at least, all donated blood should be screened for Hepatitis B virus (HBV),
Hepatitis C virus (HCV) and Human immunodeficiency virus (HIV), and syphilis ${ }^{2}$. Hepatitis B virus (HBV), hepatitis C virus (HCV), Human immune deficiency virus (HIV) and syphilis are the most important lethal agents in transfusion transmitted infections (TTIs) and it remains a large health care burden globally. The incidence rates across the world are difficult to calculate given the asymptomatic and often latent nature of the disease prior to clinical presentation ${ }^{14}$. Every blood transfusion therefore carries a potential risk for transmissible diseases ${ }^{14,15}$. Blood transfusion is a therapeutic procedure, as there is no genuine substitution. But contaminated blood transfusion can transmit infectious diseases and can be fatal instead of saving life. Safe blood transfusion services are a cornerstone of an effective high quality health care system $^{16}$ Therefore stringent screening of blood donors for TTIs is crucial to ensure safe supply of blood and blood products. ${ }^{14}$ 
The magnitude of the TTI varies from country to country depending on TTIs' loads in that particular population from where blood units are sourced. Multiple measures are taken to minimize TTI transmission in the respective population. The majority of the problems are due to the prevalence of asymptomatic carriers in the society, as well as blood donations during the window period of infections. There is a long list of viruses, parasites, and bacteria, which can be transmitted through blood transfusions. Among them, important transfusion transmitted viruses are human immunodeficiency virus (HIV-I/II), hepatitis B virus (HBV), hepatitis $\mathrm{C}$ virus (HCV), syphilis infection by Spirochaetes, and transfusion associated malaria infection "as discussed by Choudhury. ${ }^{17}$

\section{Methodology}

This study was carried out at transfusion medicine department of DMCH from 1st January 2014 to $31^{\text {st }}$ December 2014. Among total 39,512 blood donors, relative donors were 32,778 . and remaining 6,734 donors were voluntary donors. Donors were selected after proper history taking and physical examination, according to donor selection criteria. With all aseptic precaution blood collected from donors. Centrifuged the blood and separated the serum another labeled test tube Detection of HBsAg, Anti-HCV, AntiHIV, Anti- Treponema and Anti-Malaria were done by rapid device and positive tests were repeated by ELISA. All tests were performed in accordance with the instruction of reagent manufacture.

\section{Results}

In this study among 39,512 blood donors, relative blood donors were $32,778 \quad(82.95 \%)$ and voluntary blood donors were 6734. ( $17.04 \%)$ Among total blood donors male and female were $31602 \quad(79.98 \%$ )and $7910 \quad(20.01 \%)$ respectively. Age ranges of donors were $18-40$ years 35,275 (89.27\%) and $41-60$ years 4,237 $(10.72 \%)$ Frequency of $\mathrm{HBsAg}$ positive 456 (1.154\%.), Anti HCV positive 33 (.090\%), Malarial Parasite positive 4 (.010\%), Treponema pallidum positive $87(.220 \%)$ and positive for HIV 1(.00253\%)
Table-I : Distribution of types of blood donors (n-39,512)

\begin{tabular}{lll}
\hline Types of donor & Number & \% \\
\hline Relative & 32,778 & 82.95 \\
Voluntary & 6,734 & 17.04 \\
\hline
\end{tabular}

Table-II : Distribution of age of blood donors (n-39,512)

\begin{tabular}{lll}
\hline Age & Number & \% \\
\hline $18-40$ Year & 35,275 & $89.27 \%$ \\
$41-60$ Year & 4,237 & $10.72 \%$ \\
\hline
\end{tabular}

Table-III : Distribution of sex of blood donor (n-39,512)

\begin{tabular}{lll}
\hline Sex & Number & $\%$ \\
\hline Male & 31602 & $79.98 \%$ \\
Female & 7910 & $20.01 \%$ \\
\hline
\end{tabular}

Table-IV : Seropositive of HBsAg, HCV, HIV,Malaria Syphilis among healthy donors

Total donor HBsAg positive $\mathrm{HCV}$ positive HIV positive Malaria positive Syphilis positive
\begin{tabular}{ccccccc} 
& $\mathrm{n}(\%)$ & $\mathrm{n}(\%)$ & $\mathrm{n}(\%)$ & $\mathrm{n}(\%)$ & $\mathrm{n}(\%)$ \\
\hline 39,512 & $456(1.154)$ & $33(.090 \%)$ & $01(.0025 \%)$ & $04(.010 \%)$ & $87(.220 \%)$ \\
\hline
\end{tabular}

\section{Discussion}

In this study among 39,512 blood donors, relative blood donors were 32,778 (82.95\%)and voluntary blood donors were 6,734. (17.04\%) Among total blood donors male and female were 31602 (79.98\%), and $7910(20.01 \%)$ respectively. Age ranges of donors were $18-40$ years 35,275 $(89.27 \%)$ and $41-60$ years $4,237(10.72 \%)$ Frequency of HBsAg positive 456 (1.154\%), Anti HCV positive 33 ( $.090 \%)$, Malarial Parasite positive $4(.010 \%)$, Treponema pallidum positive $87(.220 \%)$ and positive for HIV 1(.00253\%).

In Bombay, HbsAg positive in $6 \%$ cases and in Pakistan it is $5 \% 3$. In one study done by Safe Blood Transfusion Center, HbsAg positive $(0.96 \%)$, HCV positive $(0.15 \%)$, HIV positive $0.0065 \%)$ TP positive $(0.15 \%)$ 4. Study in $\mathrm{KMCH}$. HbsAg positive (1.39\%), HCV positive $(0.024 \%)$, HIV positive $(0.38 \%) 5$. In a study in Canada, HBsAg positive (12.40\%), HCV positive $(16.83 \%)$, HIV positive $(0.38 \%) 6$. In a study in 
Italy $\mathrm{HBV}$ positive is $(4.86 \%) 7$. In another in Turkey, HBV positive (1.38\%), HCV (0.35\%)8.

Seroprevalence rates of $\mathrm{HBsAg}$ and anti-HCV varies different countries. Prevalence of HBsAg was found $3.4 \%$ in Georgia, $1.5 \%$ in Kingdom of Saudi Arabia, $4.3 \%$ in Egypt, $1.38 \%$ in Turkey, $0.82 \%$ in Nepal and $3.3 \%$ in Brazil ${ }^{9-10}$. A similar study was conducted in India which depicted that the prevalence rates of TTI per 100000 donations were 350 for HIV $(0.35 \%), 350$ for $\mathrm{HCV}$ $(0.35 \%, 1660$ for HBV $(1.66 \%)$ and 800 for syphilis $(0.8 \%)^{11}$. It was noted that in Ethiopia the prevalence rates of TTIs in blood donors are $4.5 \%$ for $\mathrm{HIV}, 8.2 \%$ for $\mathrm{HBV}$ and $5.8 \%$ for $\mathrm{HCV}^{12}$. In Iranian blood donors these rates were $0.003 \%, 0.487 \%, 0.093 \%$ and $0.005 \%$ for HIV, HBV, HCVand Syphilis respectively ${ }^{13}$.

\section{Conclusion}

The field of transfusion medicine has encountered huge precautions in providing safe blood. Prevention of spread of TTIs should be the main goal at the current time. It is important to follow the WHO guidelines to tests every donor for HBV, HCV, HIV and Syphilis to decrease the transmission of TTIs. Voluntary donors should be promoted and their screening should be made mandatory at each health care facility. Educating people and creating awareness about voluntary blood donation is an important factor.

\section{Conflict of interest: None}

\section{Refference}

1. Hollan SR, Wagstaff W, Leikola J, Lothe F. Management of blood transfusion services, Geneva: World Health Organization; 1990. p. 131.

2. WHO fact sheet on Blood safety and donation, 2008.

3. Raman K, Khan AA, Huda Z, et al prevalence of seromarkers of $\mathrm{HBV}$ and $\mathrm{HCV}$ in health care personal and apparently healthy blood donors. JPak Med Assoc. 46: $152-4$.

4. Safe Blood Transfusion Center. Annual reports of donor screening, DMCH, Dhaka. 2009.

5. Ahmed MU, Begum HA, Hossain T, Incidence of common transfusion transmitted disease among blood donors. JAFMC, Bangladesh. 2009; 5(1):
6. Chiavetta JA, Escobar M, et al. Incidence of HBV, HCV and HIV in Canada, CMAJ. 2003; 169(8):

7. Manjinni $P$, Guurotto $M$, et al. Italian blood donors with anti-HBc and occult HBV infection. Haematologia. 2007; 92(12):

8. The prevalence of HBV,HCV and HIV infection among donor in Ijmer, Turkey. Indian J Med

9. El-Gilani AH, El-Fidawy S. Blood born infections among student voluntary blood in Mansoura University, Egypt. East Mediterr Health J 2006; 12: 742-8.

10. Afsar J, Gungor S, Sener Ag, Yurtsever SG. The prevalence of $\mathrm{HBV}, \mathrm{HCV}$ and HIV among blood donors in Lzmir, Turkey. Indian $\mathrm{J}$ Med Microbioil 2008; 26: 288-9.

11. Bhattacharya $\mathrm{P}$, Chandra $\mathrm{PK}$, Datta S, Banerjee A, ChakravartyR.Significant increase in HBV, HCV, HIV and syphilis infections among blood donors in West Bengal, Eastern India 2004-2005: Exploratory screening reveals high frequency of $\mathrm{HBV}$ infection. World J Gastroenterol 2007; 13 (27): 3730-3.

12. Diro E, Alemu S, G/ Yohannes A. Blood safety and prevalence of transfusion transmissible viral infections among donors at Red Cross Blood Bank in Gondar University Hospital.Ethiop Med J. 2008 Jan; 46(1): 7-13.

13. Khedmat H, Fallahian F, Abolghasemei H, Alavian SM, Hajibeigi B, Miri SM, Jafari AM. Seroepidemiological study of hepatitis B virus, hepatitis $\mathrm{C}$ virus, Human immunodeficiency virus and syphilis infection in Iranian blood donors. Pak j Biol Sci. 2007 Dec.

14. Bhawani Y, Rao PR, Sudhakar V: Seroprevalence of transfusion transmissible infections among blood donors in a tertiary care hospital of Andh. Biol Med 2010, 2(4):45-48.

15. Khan S, Attaullah S, Ayaz S, Khan SN, Shams S, Ali I, et al: Molecular epidemiology of HCV among the health care workers of Khyber Pakhtunkhwa. Virol J 2011, 8(1): 105 .

16. Manzoor I, Hashmi N, Daud S: Seroprevalence of transfusion transmissible infections (TTIS) in blood donors. Biomedica 2009, 25:154-158.

17. N. Choudhury, "Transfusion transmitted infections: how many more?" Asian Journal of Transfusion Science, 2010; 4(2): 71-72. 